\title{
Advantages of Smart Phone Hearing Aids Over Traditional Hearing Aids
}

\author{
Kaleem Abbas, Atia-ur-rehman, Waris Ali, Ambreen Sadaf, Humara Waseem, Noman Tahir
}

\begin{abstract}
:
Hearing is the process by which the ear transforms sound vibrations in the external environment into nerve impulses that are conveyed to the brain, where they are interpreted as sounds. A hearing aid is a small electronic device that you wear in or behind your ear. It makes some sounds louder so that a person with hearing loss can listen, communicate, and participate more fully in daily activities. A hearing aid can help people hear more in both quiet and noisy situations. Objective: To find out the Advantages of smart phone hearing aids over traditional hearing aids.
\end{abstract}

Keywords: Audiologist, Hearing Aids, Satisfaction with Amplification in Daily Life.

DOI: $10.7176 / \mathrm{JHMN} / 85-08$

Publication date: January $31^{\text {st }} 2021$

\section{Introduction}

Hearing is crucial for human life ${ }^{8}$.it assumes a significant job in discourse and language improvement, which is the fundamental device for the advancement of human correspondence ${ }^{1}$. People with hearing impedance may endure extreme misfortune in their social, mental and proficient lives, additionally having sentiments of uncertainty, dread, misery, disengagement and furthermore family strains as a result of the absence of consideration influencing those with hearing disorders ${ }^{2}$.

A portable hearing assistant is a gadget intended to recover hearing by production sound discernable to an individual with earshot bad luck. Portable amplifiers are termed therapeutic devices in numerous nations, and managed by the detached guidelines ${ }^{3}$.Tiny comprehensive reciters, for sample, PSAPs or additional basic stable stimulating outlines can't be traded as "earshot assistances". Primary gadgets, for example, auricle announces or auricle sirens, were aloof intensification pinecones intended to assemble wide-ranging vitality and straight it interested in the ear trench. Present day gadgets are mechanized electroacoustic frameworks that change natural sound to make it perceptible, as indicated by sound metrical and intellectual principles ${ }^{4}$. Current gadgets additionally use advanced computerized signal handling to attempt and improve discourse comprehensibility and solace for the client. Such sign handling incorporates input the executives, wide powerful range pressure, directionality, recurrence bringing down, and commotion decrease ${ }^{5}$.

Simple portable amplifiers essentially take sounds and make them more intense ${ }^{6}$,similarly as measuring your hand behind your ear enhances sound. Some simple listening devices incorporate a programmable microchip, however the capacities are generally essential ${ }^{7}$.Then again, advanced portable amplifiers take in sound waves (in itself a simple sign, for the nerd people out there), make an interpretation of it into computerized group (read: heaps of 1 's and $0 \mathrm{~s}$ ), process, channel, misshape, intensify and at last convey a sound sign into your ear trench that is exclusively customized to your necessities ${ }^{9}$. So as to play out every one of these marvels, computerized listening devices contain an alleged Digital Signal Processor (DSP) chip ${ }^{10}$.To more readily comprehend advanced versus simple, consider the contrast between simple vinyl records and computerized CDs ${ }^{11}$ Vinyl records require genuinely straightforward techniques for playback, and a basic turntable and needle will work. Discs take somewhat more equipment, as the computerized data must be handled and imitated ${ }^{12}$. While there is a more prominent to do, CDs give more clear, high devotion sound ${ }^{13}$. (A few people lean toward the warm snap of a vinyl record, yet that fluff basically won't do with regards to your hearing!) These small instruments can at the same time play out an assortment of sound preparing errands. In one significant capacity, the portable amplifier rapidly recognizes discourse sounds and clamor ${ }^{14}$.All things considered, the listening device enhances discourse while diminishing commotion ${ }^{15}$. As simple listening devices enhance sounds less discriminately, a great deal of commotion can hinder a decent discussion. Advanced listening devices can be modified with a product to suit your exceptional hearing needs. Programmable simple portable hearing assistants are accessible, yet advanced innovation can give a far more noteworthy level of adjusting ${ }^{16}$. Better programming methods better solid preparing in various sound situations - from a tranquil library to an uproarious eatery ${ }^{17}$. Notwithstanding more extensive programming alternatives, computerized amplifiers have the limit with regards to additional highlights, for example, Bluetooth and telecoil innovation. Input decrease is one of the best points of interest to advanced amplifiers ${ }^{18}$.Similarly computerized listening devices can recognize sound and discourse, these clever little gadgets can foresee and decrease input. Computerized innovation enables the listening device to limit or totally counteract any identified criticism, so you can maintain a strategic distance from difficult whistling sounds. ${ }^{19}$ 


\section{Methods:}

Cross-sectional study was conducted among Hearing aid users with conventional hearing aid and hearing aid users with mobile application using purposive sampling technique SADL (Satisfaction with amplification in daily life) was used to assess the adnantages between conventional hearing aid users and hearing aid users with mobile application.50 applicants with moderate to severe SNHL recommended for hearing aid fitting were included in this research by their consent. The data of 100 participants were analyzed through SPSS version 25 .O and P-value less than 0.05was considered significant.After collecting data it was analyzed through SPSS version 25.0.Descriptive (mean, standard deviation and minimum, maximum) statistics were used to analyze variables i.e. age weight height and working hours a week. Demographics (age, gender ,occupation)and to find out the advantages of conventional hearing aid users and hearing aid users with mobile application were analyzed using frequencies and percentage and independent t-test.

\section{Results}

A total number of $100(100 \%)$ of hearing aid candidates were included in this study which were equally distributed by gender as 50(50\%) were male participants and 50(50\%) were female participants Independent models test was applied to calculate the significant difference among participants satisfaction by using mobile application controlled hearing aids and Traditional hearing aids. Level of significance difference was taken $<0.005$ and results suggest that level of significance between using mobile application controlled hearing aids and Traditional hearing aids is less than $<0.005$ which supports our alternative hypothesis that level of satisfaction in mobile app-controlled hearing aid users is greater than traditional hearing aid users. the level of satisfaction between smart phone hearing aid users and traditional hearing aid users indicates that the smart phone hearing aid have more advantages in daily routine.

\begin{tabular}{|r|l|r|r|r|r|}
\hline \multicolumn{7}{|c|}{} \\
\hline \multicolumn{2}{|c|}{ Gender of the patient } \\
\hline \multirow{3}{*}{ Valid } & \multicolumn{2}{|c|}{ Frequency } & Percent & Valid percent & Cumulative percent \\
\cline { 2 - 7 } & male & 50 & 50.0 & 50.0 & 50.0 \\
\cline { 2 - 7 } & female & 50 & 50.0 & 50.0 & 100.0 \\
\cline { 2 - 7 } & total & 100 & 100.0 & 100.0 & \\
\hline
\end{tabular}

Table 1: Descriptive statistics of gender

A total number of $100(100 \%)$ of hearing aid candidates were included in this study which were equally distributed by gender as $50(50 \%)$ were male participants and $50(50 \%)$ were female participants

\begin{tabular}{|l|l|r|r|r|r|}
\hline \multicolumn{9}{|c|}{ group statistics } \\
\hline & Category & $\mathrm{N}$ & Mean & \multicolumn{1}{c|}{ Std. deviation } & \multicolumn{1}{c|}{ Std. Error mean } \\
\hline \multirow{2}{*}{ Total } & without app & 46 & 48.0000 & 3.91578 & .57735 \\
\cline { 2 - 6 } & with app & 48 & 53.9583 & 4.17673 & .60286 \\
\hline
\end{tabular}

Table 2: Descriptive statistics of groups

The participants who were using traditional hearing aids there the level of satisfaction was $48.0 \pm 3.91$ and the level of satisfaction in participants who were using smart phone hearing aidswas $53.95 \pm 4.17$.there is a significant difference in the level of satisfaction between smart phone hearing aid users and traditional hearing aid users which indicates ,smart phone hearing aid have more advantages as compare to the traditional hearing aids.

\begin{tabular}{|c|c|c|c|c|c|c|c|c|c|c|}
\hline \multicolumn{11}{|c|}{ independent samples test } \\
\hline & & \multicolumn{2}{|c|}{$\begin{array}{c}\text { Levene's Test for } \\
\text { equality of } \\
\text { variances }\end{array}$} & \multicolumn{7}{|c|}{ t-test for equality of means } \\
\hline & & \multirow[t]{2}{*}{$\mathrm{F}$} & \multirow[t]{2}{*}{ Sig. } & \multirow[t]{2}{*}{$\mathrm{T}$} & \multirow[t]{2}{*}{ Df } & \multirow[t]{2}{*}{$\begin{array}{l}\text { Sig. (2- } \\
\text { tailed) }\end{array}$} & \multirow[t]{2}{*}{$\begin{array}{c}\text { mean } \\
\text { difference }\end{array}$} & \multirow[t]{2}{*}{$\begin{array}{l}\text { Std. Error } \\
\text { Difference }\end{array}$} & \multicolumn{2}{|c|}{$\begin{array}{l}95 \% \text { confidence } \\
\text { interval of the } \\
\text { difference }\end{array}$} \\
\hline & & & & & & & & & Lower & upper \\
\hline \multirow{2}{*}{ total } & $\begin{array}{l}\text { equal } \\
\text { variances } \\
\text { assumed }\end{array}$ & .018 & .895 & -7.128 & 92 & .000 & -5.95833 & .83589 & -7.61847 & -4.29819 \\
\hline & \begin{tabular}{|l|} 
equal \\
variances not \\
assumed
\end{tabular} & & & -7.138 & 91.958 & .000 & -5.95833 & .83473 & -7.61619 & -4.30048 \\
\hline
\end{tabular}

Table 3: independent t-test 
Independent models test was applied to calculate the significant difference among smart phone hearing aid users and traditional hearing aid users. Level of significance difference was taken $<0.005$ and results suggest that level of significance among smart phone hearing aid users and traditional hearing aid user is less than $<0.005$ which supports our alternative hypothesis that level of satisfaction in mobile app-controlled hearing aid users is greater than traditional hearing aid users.

\section{Discussion}

The determination of study was to equate the advantages between smart phone based self-controlled Hearing aid users and traditional Hearing aid users. This study was carried out in sialkot audiology clinic Sialkot Pakistan, which includes the participants who were the candidates of hearing aid fitting. Discussion involves following domains methodology, study settings, provision of hearing aids with and without mobile application controlled. The findings indicate that satisfaction levels in patients having mobile phone-based self-control is highly significant as compared to the participants using traditional hearing aids which means smart phone based hearing aid have more advantages as compared to the traditional hearing aids. While the majority reported in previous researches shows that the satisfaction with the hearing aid increased when it provides Self-control to the participants using hearing aids as they can adjust their required amplification in regard to their environmental conditions ${ }^{20}$. for this purpose, SADL (Satisfaction with Amplification in Daily Life) a standard questionnaire was used its validity to measure satisfaction with amplification in daily life was measured in previous research by Holly Hosford-Dunn* Jerry Halpern' titled as ${ }^{21}$ "clinical application of the satisfaction with amplification in daily life Scale in Isolated Exercise I: ${ }^{22}$ Statistical, Content, and Factorial Validity" published in J Am Acad Audiol 11: 523539 (2000). Measurable, substance, and factorial legitimacy of the Satisfaction with Amplification in Daily Life (SADL) scale was surveyed. SADL subscales intently compare to four fulfillment spaces. Emotional advantage is a key part of fulfillment, however other nonauditory factors add to wearer fulfillment, remarkably phone use and appearance ${ }^{23}$. Results affirm the SADLs psychometric properties and check its utilization to approve portable amplifier fitting fulfillment in private practice settings for a general patient populace at 1-year post fitting. Break SADL standards might be refined as more SADL information are acquired for various patient populaces, listening device types, and fitting conditions ${ }^{24}$. The SADL poll and a Client Satisfaction Survey (CSS) were circulated via mail to 1284 grown-ups fitted with government-subsidized listening devices three to a half year previously.1014 reviews were returned. The mean time of members was 75.32 years; $54.4 \%$ of members were male, and $54.8 \%$ were fitted binaurally. Members were fitted principally with carefully programmable listening devices of different styles (22.5\% BTEs, 34.8\% ITEs, $41.8 \%$ ITCs, 0.9\% nonstandard [NS] gadgets). Generally, members revealed an extensive dimension of fulfillment with their gadgets. SADL Global and subscale scores were altogether higher for the Australian example than the U.S. standards portrayed by Cox and Alexander (1999).In this investigation directed to look at the dimension of fulfillment among cell phone based self-controlled listening device clients and trawls to research portable hearing assistant fulfillment for a gathering of more established Australians fitted with government-supported listening devices utilizing the Satisfaction with Amplification in Daily Life (SADL) poll ${ }^{25}$; tos contrast the Australian information assembled and the temporary regulating information detailed by Cox and Alexander (1999); and to explore the connection between SADL fulfillment and a few member factors, amplifier factors, and other result measures. In this investigation directed to look at the dimension of fulfillment among cell phone based self-controlled listening device clients and trequal of gratification in mobile phone based selfcontrolled hearing aid users and traditional hearing aid users by using SADL questionnaire which supports our objective that level of satisfaction is more significant in participants using app based self-controlled hearing aid as compared to traditional hearing aid ${ }^{26}$.

\section{Conclusion}

This study concludes that smart phone based hearing aids hove more advantages as compared to traditional hearing aids. Smart phone hearing aid have more advantages due to having more self-control on hearing aid to adjust it according to situation and enjoyment.

\section{References}

${ }^{1}$ Kochkin S. 10-year customer satisfaction trends in the US hearing instrument market. Hearing Review. 2002;9(10):14-25.

${ }^{2}$ Baker BL, Blacher J, Crnic KA, Edelbrock C. Behavior problems and parenting stress in families of three-yearold children with and without developmental delays. American Journal on Mental Retardation. 2002;107(6):433-44.

${ }^{3}$ Newman CW, Sandridge SA. Benefit from, satisfaction with, and cost-effectiveness of three different hearing aid technologies. American Journal of Audiology. 1998.

${ }^{4}$ Wolf LC, Noh S, Fisman SN, Speechley M. Brief report: Psychological effects of parenting stress on parents of autistic children. Journal of autism and developmental disorders. 1989;19(1):157-66. 
${ }^{5}$ Dillon H, James A, Ginis J. Client Oriented Scale of Improvement (COSI) and its relationship to several other measures of benefit and satisfaction provided by hearing aids. Journal-American Academy of Audiology. 1997;8:27-43.

${ }^{6}$ Humes LE, Wilson DL, Humes L, Barlow NN, Garner CB, Amos N. A comparison of two measures of hearing aid satisfaction in a group of elderly hearing aid wearers. Ear and hearing. 2002;23(5):422-7.

${ }^{7}$ Koegel RL, Schreibman L, Loos LM, Dirlich-Wilhelm H, Dunlap G, Robbins FR, et al. Consistent stress profiles in mothers of children with autism. Journal of autism and developmental disorders. 1992;22(2):205-16.

${ }^{8}$ Waldmann B. Method and system for hearing device fitting. Google Patents; 2010.

${ }^{9}$ Ambrose SD, Gido SP, Schulein RB. Hearing Device System and Method. Google Patents; 2012.

${ }^{10}$ Shugart III MW. Hearing aid device. Google Patents; 1994.

${ }^{11}$ Meier H, Boretzki M, Bächler H, Launer S. Method for adapting a hearing device to a momentary acoustic situation and a hearing device system. Google Patents; 2008.

${ }^{12}$ Akiyama T. Plug-type hearing device. Google Patents; 1979.

${ }^{13}$ Hough J, Matthews P, Wood MW, Dyer Jr RK. Middle ear electromagnetic semi-implantable hearing device: results of the phase II SOUNDTEC direct system clinical trial. Otology \& neurotology. 2002;23(6):895-903.

${ }^{14}$ Rueda VC. Communication system including a hearing aid and a language translation system. Google Patents; 2000.

${ }^{15}$ Francart T, Wouters J, Van Dijk B. Localisation in a bilateral hearing device system. Google Patents; 2013.

${ }^{16}$ Hohmann V, Hamacher V, Holube I, Kollmeier B, Wittkop T. Method for the operation of a hearing aid device or hearing device system as well as hearing aid device or hearing device system. Google Patents; 2006.

${ }^{17}$ Stanton MF. Modular hearing aid system. Google Patents; 1993.

${ }^{18}$ Chen DA, Backous DD, Arriaga MA, Garvin R, Kobylek D, Littman T, et al. Phase 1 clinical trial results of the Envoy System: a totally implantable middle ear device for sensorineural hearing loss. Otolaryngology-Head and Neck Surgery. 2004;131(6):904-16.

${ }^{19}$ Zhang C, Hou Z. Method and system for remotely upgrading a hearing aid device. Google Patents; 2007.

${ }^{20}$ Meier H, Launer S. Method for adjusting a hearing device to a momentary acoustic surround situation and a hearing device system. Google Patents; 2006.

${ }^{21}$ Holmes D. Wireless hearing aid system and method. Google Patents; 2007.

${ }^{22}$ Leysieffer H, Rinser G. Partially or fully implantable hearing system. Google Patents; 2003.

${ }^{23}$ Jensen J, Pedersen MS. Self-calibration of multi-microphone noise reduction system for hearing assistance devices using an auxiliary device. Google Patents; 2017.

${ }^{24}$ Lidén G, Jacobsson M, Håkansson B, Tjellström A, Carlsson P, Ringdahl A, et al. Ten years of experience with the Swedish bone-anchored hearing system. Annals of Otology, Rhinology \& Laryngology. 1990;99(10_suppl):1-16.

${ }^{25}$ Pavlovic CV, Edwards BW, Perkins R, Cohen E, Michael NR. Personalized sound system hearing profile selection process. Google Patents; 2012.

${ }^{26}$ Zarowski A, Van Ruiten N. Implantable hearing system. Google Patents; 2009. 